\title{
Wave-induced nearshore circulation along the Calangute-Candolim beach, Goa, west coast of India
}

\author{
V KRISHNA KUMAR, C S MURTY and A K HEBLEKAR* \\ National Institute of Oceanography, Dona Paula, Goa 403004, India \\ * PES College of Arts and Science, Ponda, Goa 403 405, India \\ MS received 14 September 1988; revised 24 July 1989
}

\begin{abstract}
The wave-induced nearshore circulation model suggested by Noda has been modified and applied for three small segments along the coast of Goa. The present model incorporates the prevailing bottom topography and considers its variation along with the radiation stress as the driving force for the circulation. We find that the flow pattern is strongly dependent on bottom topography. While normal incidence of waves results in a cellular pattern of flow, meandering flows prevail for oblique incidence along the coast. The shoreward flows are always located over shoals while the rip currents prevail over channels. The onshore/offshore flows show magnitudes as high as $3.1 \mathrm{~m} / \mathrm{s}$, while those alongshore reach a maximum of $1.1 \mathrm{~m} / \mathrm{s}$. When compared with field observations these values are slightly higher.
\end{abstract}

Keywords. Nearshore circulation; radiation stress; stream function; rip current; CalanguteCandolim beach.

\section{Introduction}

Information, either through field observations or by theoretical analysis of nearshore flows, especially within the first breaker and the shoreline, is very limited along the coasts of India. The study becomes important when one considers coastal management problems, such as, the development of fishing harbours, creation of shore based facilities for offshore oil fields, planning the discharge of effluents and sewage from industries and townships into the sea and the development of recreational facilities along the beaches.

Over the past two decades, studies on the dynamics of nearshore regions have been advanced by mathematical models (Bowen 1969a, b; Thornton 1971; Noda 1974 and Longuet-Higgins $1970 \mathrm{a}, \mathrm{b}$ ). These models are based on the concept of radiation stress advanced during the early sixties (Longuet-Higgins and Stewart 1964). With the advent of fast computers, the numerical models have become very handy for solving the governing equations. These models, once calibrated with field data, can be applied to practical problems.

In this article, we present the results of a numerical model on the nearshore flow of water limited to three small segments $(100 \mathrm{~m}$ each in length) of the coastline along the coast of Goa (figure 1). The model is an adoption of the one suggested by Noda (1974), but with a major modification making it more flexible and realistic. The variations in wave characteristics resulting from changing bottom topography and the excess flow of momentum due to the presence of waves (radiation stress) are considered to be the main driving forces for the circulation. Noda (1974) generated 


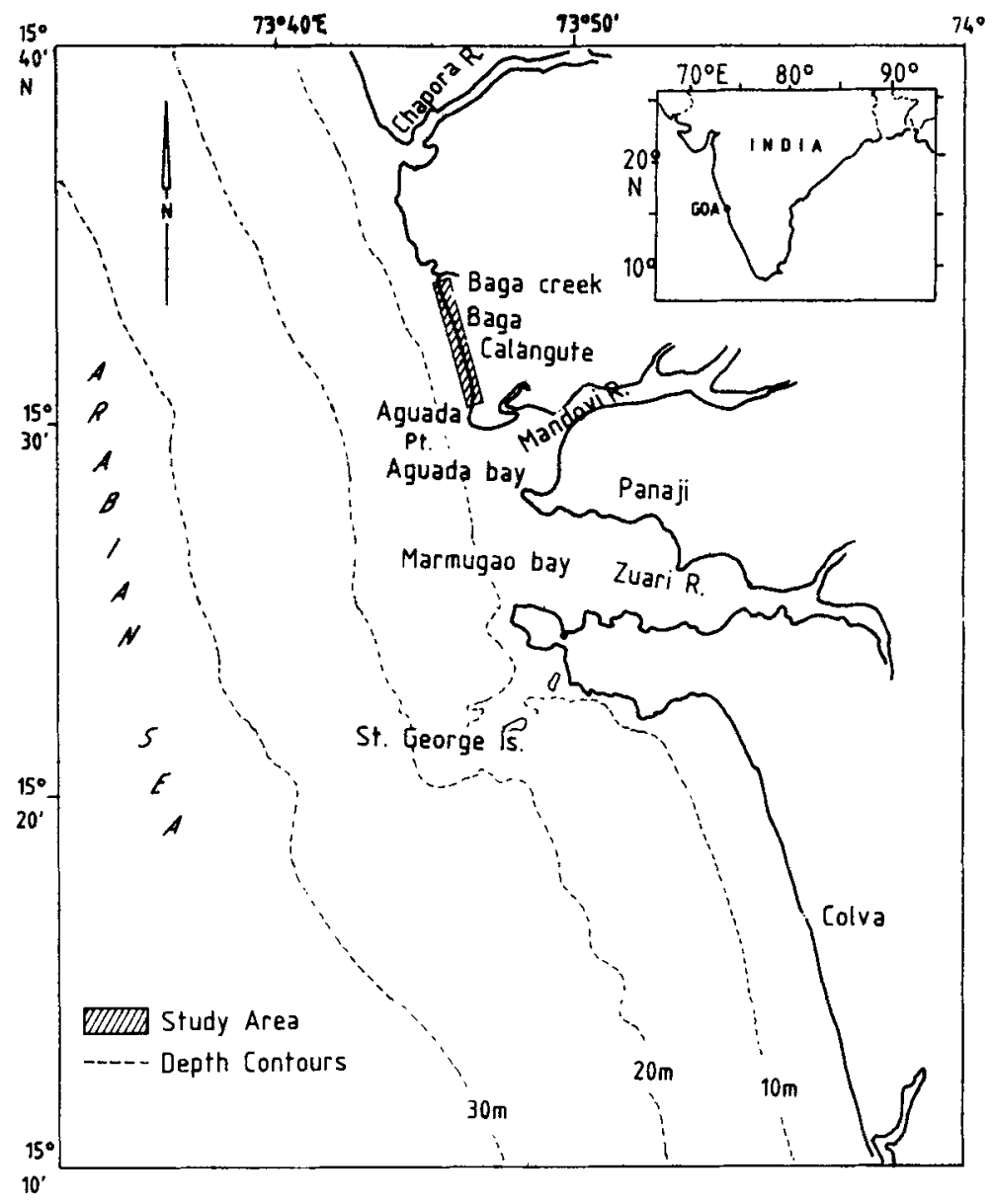

Figure 1. Study area.

periodic and skewed bottom topography to give more reality to the model compared to the parallel bottom topography through analytic equations of Bowen $(1969 a, b)$. The results were encouraging when compared with field observations of Sonu (1972). The major modification made in the present study is by way of incorporating real bathymetry as against the above and makes the model more flexible.

\section{Governing equations}

The equations of motion and continuity for a homogeneous incompressible fluid are

$$
\begin{aligned}
& g \frac{\partial \eta}{\partial x}+M_{X}+F_{X}=0, \\
& g \frac{\partial \eta}{\partial y}+M_{Y}+F_{Y}=0, \\
& \frac{\partial}{\partial x}[u(\eta+d)]+\frac{\partial}{\partial y}[v(\eta+d)]=0,
\end{aligned}
$$




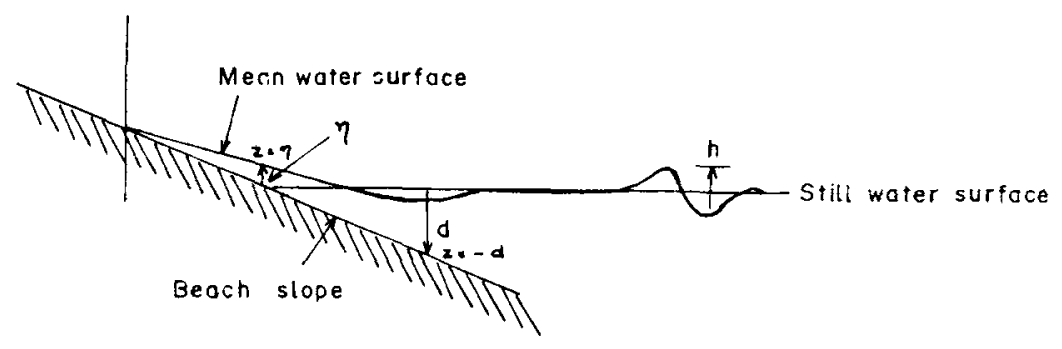

Figure 2. Schematic diagram (elevation view) showing $\eta, h$ and $d$.

where $\eta$ is the difference between the still water level and the mean sea level in the presence of waves (figure 2 ) and $g$ is the acceleration due to gravity. $M_{X}$ and $M_{Y}$ are the radiational stress components (Longuet-Higgins and Stewart 1964) expressed by

$$
\begin{aligned}
& M_{X}=-\frac{1}{\rho(\eta+d)}\left(\frac{\partial}{\partial x} S_{X X}+\frac{\partial}{\partial y} S_{X Y}\right), \\
& M_{Y}=-\frac{1}{\rho(\eta+d)}\left(\frac{\partial}{\partial y} S_{Y Y}+\frac{\partial}{\partial x} S_{Y X}\right) .
\end{aligned}
$$

The radiation shear stress term

$$
S_{X Y}=S_{Y X}=\int_{-d}^{\eta} \overline{\rho u v \mathrm{~d} z},
$$

(where $z$ denotes the distance measured upward from the mean surface, so that at the bottom $z=-d$ and the free surface $z=\eta$ ) which is equal to zero in the case of normal wave incidence, but for oblique wave approach there will be a non-zero shear stress term. Its magnitude may be calculated by the ordinary tensor transformation rules from the two-dimensional tensor $S$, which in diagonal form is given by

where

$$
S=E\left(\begin{array}{cc}
\frac{2 k d}{\sinh 2 k d}+\frac{1}{2} & 0 \\
0 & \frac{k d}{\sinh k d}
\end{array}\right),
$$

$$
E=\frac{1}{8} \rho g h^{2}
$$

the energy density. Thus

where

$$
\begin{aligned}
& S_{X Y}=S_{Y X}=\left(\frac{1}{16}\right) \rho g h^{2} n \sin 2 \theta, \\
& S_{X X}=\left(\frac{1}{8}\right) \rho g h^{2}\left[\left(2 n-\frac{1}{2}\right) \cos ^{2} \theta+\left(n-\frac{1}{2}\right) \sin ^{2} \theta\right], \\
& S_{Y Y}=\left(\frac{1}{8}\right) \rho g h^{2}\left[\left(2 n-\frac{1}{2}\right) \sin ^{2} \theta+\left(n-\frac{1}{2}\right) \cos ^{2} \theta\right],
\end{aligned}
$$

$$
n=\frac{1}{2}+[k d / \sinh 2 k d]
$$

$F_{X}$ and $F_{Y}$ are the frictional terms arising from a linearized bottom friction coefficient $\bar{c}$ given by

$$
F_{X}=\frac{2 \bar{c} h u}{(\eta+d) T \sinh k d}
$$




$$
F_{Y}=\frac{2 \bar{c} h v}{(\eta+d) T \sinh k d},
$$

where $k$ is the local wave number $2 \pi / L ; \rho$ is the water density; $T$ the wave period and $L$ the local wave length.

For shallow water $n=1$ since $k d$ is small. Thus,

$$
\begin{aligned}
& S_{X X}=\left(\frac{1}{16}\right) \rho g h^{2}\left(3 \cos ^{2} \theta+\sin ^{2} \theta\right), \\
& S_{Y Y}=\left(\frac{1}{16}\right) \rho g h^{2}\left(3 \sin ^{2} \theta+\cos ^{2} \theta\right), \\
& S_{X Y}=S_{Y X}=\left(\frac{1}{16}\right) \rho g h^{2} \sin 2 \theta .
\end{aligned}
$$

Introducing a stream function $\psi$ defined by

$$
\begin{aligned}
& \partial \psi / \partial x=+v d \\
& \partial \psi / \partial y=-u d
\end{aligned}
$$

and cross-differentiating (1) and (2) and also assuming that $\eta+d \approx d$, we get the following circulation equation (Noda 1974),

where

$$
\begin{aligned}
& \frac{\partial^{2} \psi}{\partial x^{2}}+\frac{\partial^{2} \psi}{\partial y^{2}}+\frac{\partial F / \partial y}{F} \frac{\partial \psi}{\partial y}+\frac{\partial F / \partial x \partial \psi}{F} \frac{\partial \psi}{\partial x} \\
& \quad=\frac{g}{F}\left\{\frac{\partial}{\partial y}\left[\frac{1}{d}\left(\frac{\partial}{\partial x} \bar{S}_{X X}+\frac{\partial}{\partial y} \bar{S}_{X Y}\right)\right]-\frac{\partial}{\partial x}\left[\frac{1}{d}\left(\frac{\partial}{\partial y} \bar{S}_{Y Y}+\frac{\partial}{\partial x} \bar{S}_{Y X}\right)\right]\right\},
\end{aligned}
$$

$$
\begin{aligned}
F & =2 \bar{c} h /\left(\mathrm{d}^{2} T \sinh k d\right), \\
\bar{S}_{X X} & =h^{2}\left(\frac{3}{16} \cos ^{2} \theta+\frac{1}{16} \sin ^{2} \theta\right), \\
\bar{S}_{Y Y} & =h^{2}\left(\frac{3}{16} \sin ^{2} \theta+\frac{1}{16} \cos ^{2} \theta\right)
\end{aligned}
$$

and

$$
\bar{S}_{X Y}=\bar{S}_{Y X}=\frac{1}{16} h^{2} \sin 2 \theta \text {. }
$$

(Please see list of symbols for details.)

\section{Method}

The data required for computations are the water depth, wave height and the direction of wave approach at grid points. The predominant wave directions and periods of the study area are obtained from an atlas (Anon 1982) and from the Indian Daily Weather Reports published by the India Meteorological Department. It was found that waves with periods $6,8,10$ and 12 seconds approaching from directions WNW, $\mathrm{W}$ and WSW have higher frequencies than the rest.

A rectilinear grid was chosen for the entire Calangute stretch and a detailed analysis of wave refraction was carried out for the predominant wave characteristics (Krishna Kumar 1987) to understand the differences in energy levels and probable longshore' offshore currents. Nine stations were arbitrarily fixed (figure 3) approximately $800 \mathrm{~m}$ apart. At stations 4 (Calangute) and 6 (Candolim) rip currents are quasi-permanent 


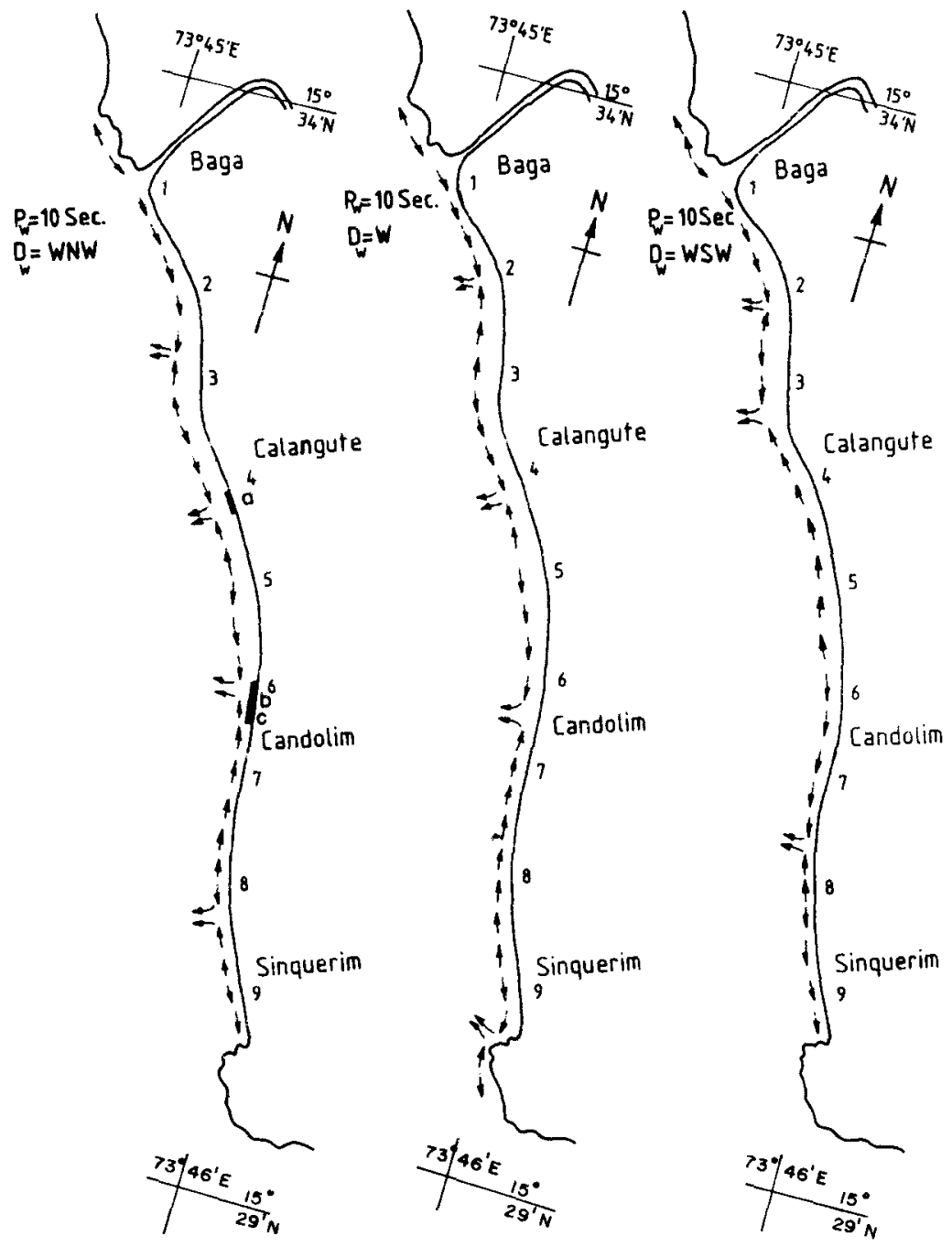

Figure 3. Probable longshore current directions for waves with $10 \mathrm{~s}$ period and approaching from WNW, W and WSW $\left(P_{w^{\prime}}=\right.$ period of the wave and $D_{w}=$ direction of the wave). Area $a$ (Calangute), $b$ (Candolim II) and $c$ (Candolim I) show areas of quasi-permanent rip currents. Figures 1 to 9 along the coast show arbitrary station positions.

for waves approaching from the $\mathrm{W}$ and WNW with a period of 10 s (figure 3). At Candoim, the extent to which the current system prevails was found to be a little spread out when compared with Calangute. These two areas divided into three segments of $100 \mathrm{~m}$ length each, namely, Calangute (a), Candolim I (b) and Candolim II (c) (figure 3) for computational convenience. Keeping the $Y$ axis parallel $(100 \mathrm{~m})$ and $X$ axis normal $(200 \mathrm{~m})$ to the shoreline, a unit grid size of $5 \mathrm{~m} \times 5 \mathrm{~m}$ was selected to obtain maximum accuracy within the limits of computation.

Ray paths were constructed for these two regions from the offshore boundary of the grid $(200 \times 100 \mathrm{~m})$ using the wave parameters obtained from the earlier study of wave refraction. This was the input for both normal (W) and oblique (WNW) incidence 
HORIZONTAL SCALE
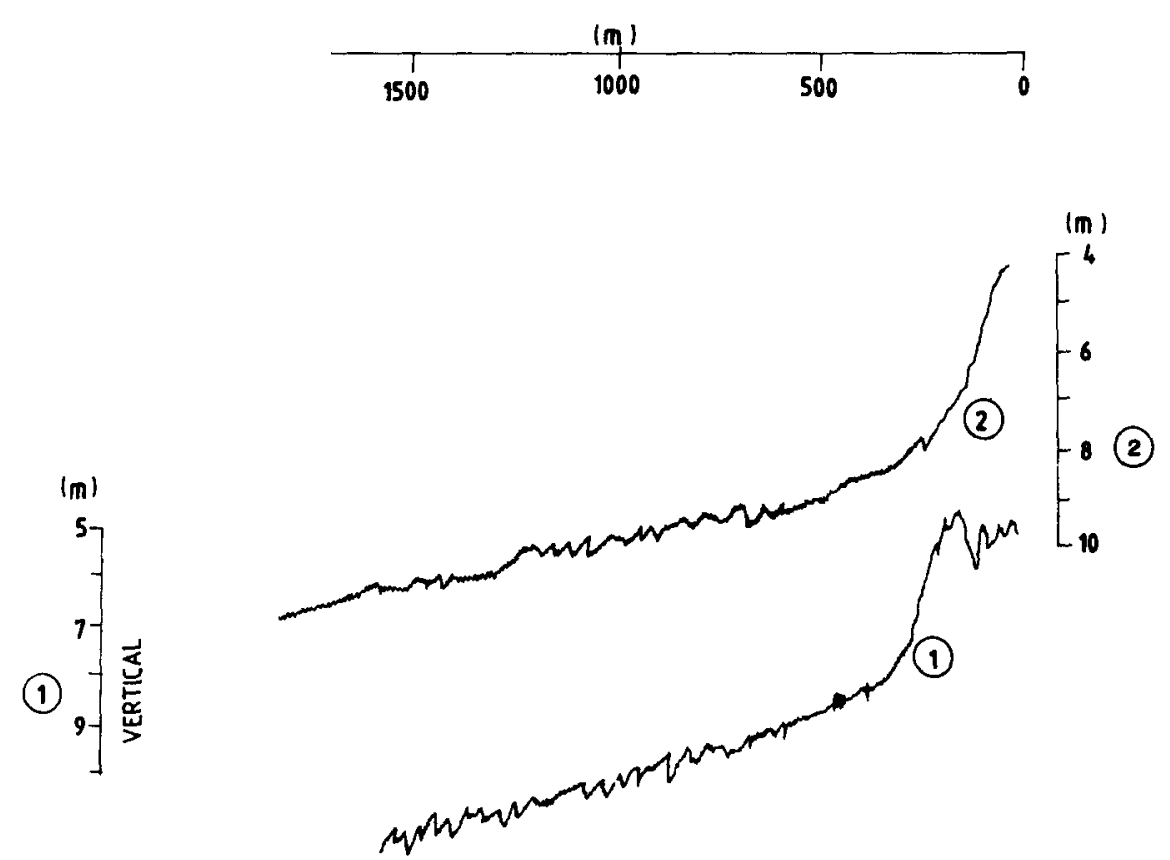

Figure 4. Nearshore bottom profile off Candolim (1) and Calangute (2) (after Veerayya 1978).

of waves. The bottom topography for these regions was obtained from bathymetric chart Nos. 2022 and 215 (NHO, corrected upto 1977 and 1983 respectively) and also from the data (figure 4) obtained with a shallow water echo sounder for these two regions (Veerayya 1978). The bottom topography shows a near periodic nature. The whole stretch of Candolim consists of two wavelengths $(\lambda)$ of bottom topography in $200 \mathrm{~m}$ whereas that of Calangute consists of only one in $100 \mathrm{~m}$ length. For simplicity of computation, only one wavelength of bottom topography was considered at a time.

A check for wave breaking $h_{b}=0.83 d_{b}$ (25) (Galvin 1972), where $h_{b}$ is the breaker height and $d_{b}$ is the breaker depth, was continually applied while tracing the wave ray to obtain the breaker line. After breaking, the wave heights were linearly made smooth up to shoreline using the relation $h=\gamma m \times$ (26) (Noda 1974) where $h$ is the wave height, $\gamma$ is an empirical constant $(0.75)$ and $m$ is the slope of the beach. The wave height $(h)$ and direction $(\theta)$ along the path of the rays were interpolated onto grid points. Along with the depth $(d)$ they form the main input data for the nearshore circulation. The constant friction coefficient suggested by Longuet-Higgins (1970a, 1972) $\bar{c}=0.01$ was used for computing the stream function $(\psi)$.

The assumptions made while considering the conditions inside the surf zone (Arthur 1962) are: (i) the circulation is steady and time-averaged and mean wave characteristics are considered, (ii) the waters of the surf zone are homogeneous and incompressible, (iii) the horizontal velocities (onshore/offshore and alongshore), $u(x, y)$ and $v(x, y)$ are independent of depth so that the equation of continuity can be integrated with depth, (iv) nonlinear terms in the induced velocity field are neglected along with the Coriolis 
force, (v) energy dissipation for the induced circulation occurs through bottom friction with an empirical constant and (vi) the circulation velocities are assumed to be small, so that the incoming wave current interactions can be neglected.

For small amplitude waves Longuet-Higgins (1972) showed that the fluxes of energy and momentum are related by the expression

$$
S_{X Y}=(\sin \theta / C) E_{X},
$$

where $E_{X}=E c_{g}$, is the flux of energy and $S_{X Y}$ is the radiation shear stress term. The factor $(\sin \theta / C)$ is a constant by Snell's law and outside the surf zone, $E_{X}$ is also a constant; consequently $S_{X Y}$ is constant. Thus everywhere outside the surf zone, the waves exert a lateral thrust on water. When $\theta=0$, according to equation (27) $S_{X Y}=0$, and there will be no force exerted on the fluid, whereas within the surf zone the variations in the radiation stress provide the necessary driving force for the steady flow in the presence of waves (Bowen 1969a, b; Longuet-Higgins 1970a, b and Thornton 1971). For the present, there is no resultant gradient of stress outside the surf zone; therefore, there is no driving term for a longshore current.

Assuming the longshore currents are steady and constant in the longshore direction, one can expect a balance of forces between (a) the driving force, (b) the dissipation by bottom friction and (c) the lateral friction.

$\psi$ was computed from (20) by the Gauss-Siedel relaxation. The newly computed value of $\psi$ is compared with the previously computed one and checked for convergence. This procedure was continued till the stream function values converge.

\subsection{Boundary conditions}

For normal incidence of waves where the bottom contours are parallel, that is, $\partial d / \partial y=0$, wave rays are normal to the shoreline $(\psi=0)$. Shoreline and offshore cut-off boundary are also defined to be the limit of computation $(\psi=0)$. But for the oblique incidence of waves, where $\partial d / \partial y=0, \psi \neq 0$ as flow is expected in the longshore direction everywhere. If $\lambda$ is the wavelength of the bottom topography, the distribution of $\psi$ must be specified along two lines of constant $Y$ spaced $\lambda$ apart. A simple iterative technique was used for solving this. Relaxation by Gauss-Siedel's method was used to continually update the value of $\psi$ after each iteration not only at interior points but also at boundary points. The value of $\psi$ along those lines can be specified as

$$
\psi\left(y_{b}, x\right)=\psi\left(y_{b}+\lambda, x\right)
$$

where $Y_{b}$ is a specific constant indicating one of the boundary lines. In this case, along the shoreline and the offshore boundary, a reference value of $\psi=0$ has been assigned. The stream function values converged after around 800 iterations in all the cases.

\section{Results and discussion}

The maximum nearshore current velocities (onshore/offshore and alongshore) for the three regions for both oblique and normal incidence of waves have been presented in table 1. The stream function solution for all the cases are presented in figures 5 to 10 . For normal incidence of waves only half the circulation cell is presented ( $Y=0$ to 50 ), as the other part is only a mirror image of the first part and $\psi$ is 
Table 1. Model values of nearshore currents.

\begin{tabular}{lcccc}
\hline & & $\begin{array}{c}\text { Onshore } \\
(\mathrm{m} / \mathrm{s})\end{array}$ & $\begin{array}{c}\text { Offshore } \\
(\mathrm{m} / \mathrm{s})\end{array}$ & $\begin{array}{c}\text { Alongshore } \\
(\mathrm{m} / \mathrm{s})\end{array}$ \\
\hline \multirow{3}{*}{ Candolim I } & N.I & 2.81 & 2.93 & 0.90 \\
& O.I & 2.73 & 2.70 & 0.93 \\
Candolim II & N.I & 2.95 & 3.01 & 0.97 \\
& O.I & 2.91 & 2.88 & 1.02 \\
Calangute & N.I & 3.12 & 3.23 & 1.04 \\
& O.I & 3.00 & 2.95 & 1.14
\end{tabular}

$N . I=$ normal incidence; $O . I=$ oblique incidence.

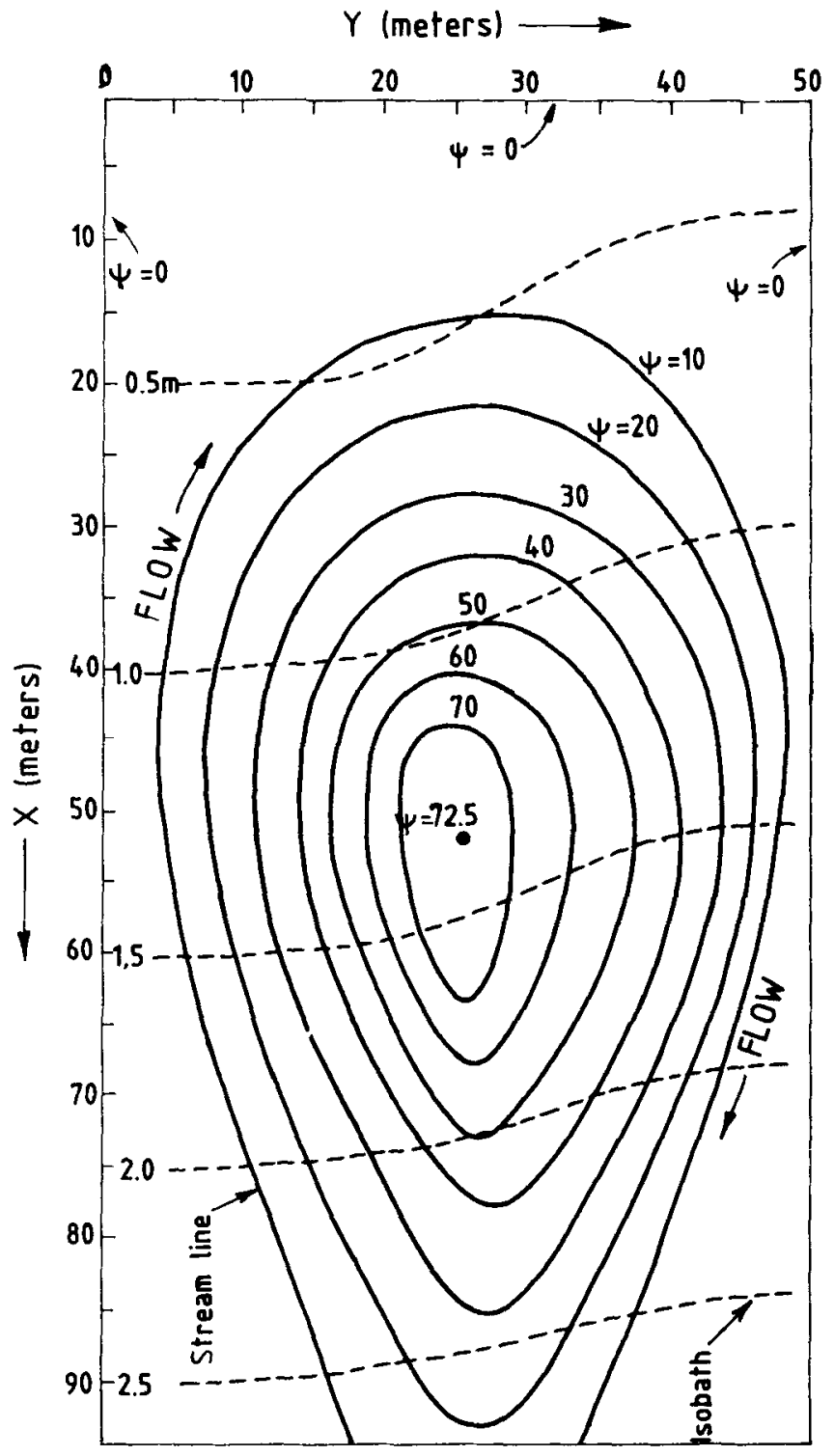

Figure 5. Stream function $\left(\mathrm{m}^{3} \mathrm{~s}^{-1}\right)$ for Candolim I (normal wave incidence). 
Wave-induced nearshore circulation
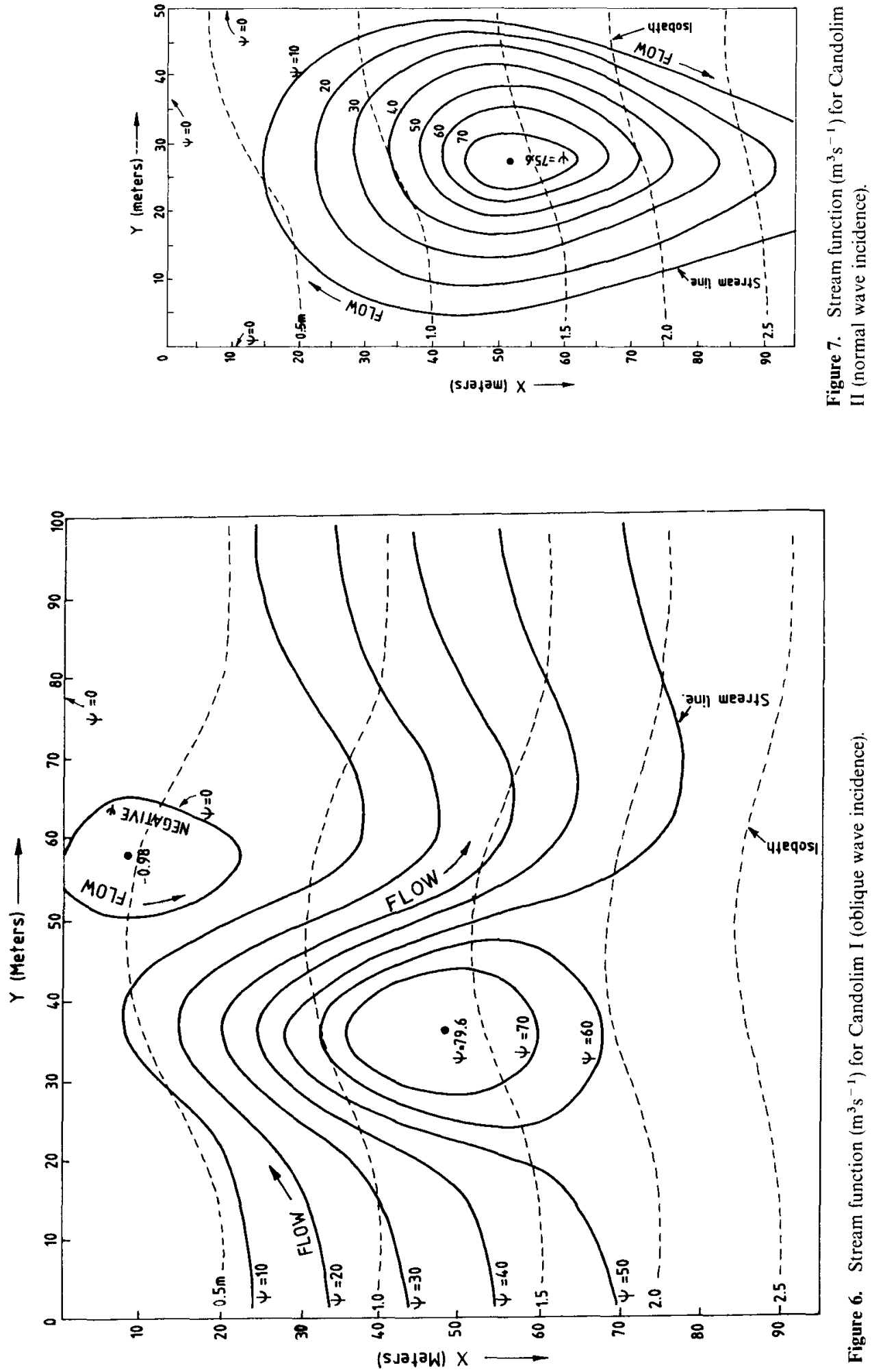


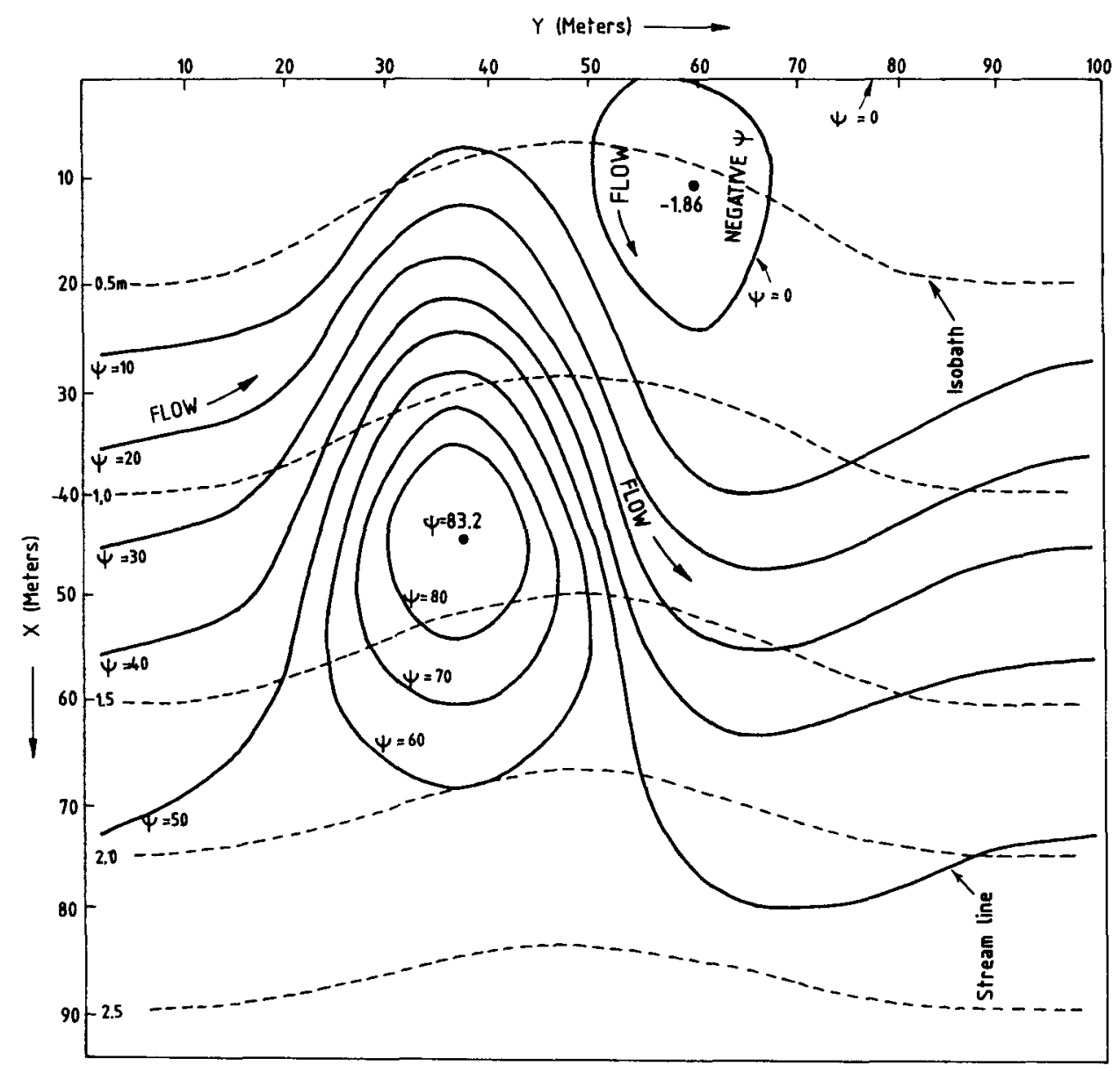

Figure 8. Stream function $\left(\mathrm{m}^{3} \mathrm{~s}^{-1}\right)$ for Canodlim II (oblique wave incidence).

negative. In all the cases shoreward flows are located over shoals and the seaward flows (rip currents) over the channels. The dependancy of the magnitude of flow velocities on bottom topography can be easily proved while examining them for different cases. Of the three cases, Calangute shows more skewed topography, thus high magnitudes are encountered here. Normal incidence of waves produce rip current cells along the coast. When waves are incident obliquely, these cells are found to be interconnected giving rise to meandering flows. For normal incidence, the rip current velocities are found higher while the longshore velocities are higher for oblique incidence of waves in all the cases.

A small negative valued $\psi$ field is observed near the shoreline at about $60 \mathrm{~m}$ (figures 8 and 10) for oblique incidence of waves. This may be the degeneration of negative-valued cell in the case of normal incidence. It may be noted that the rip current velocities are highest at about 50-60 m away from the coast (rip neck), then they diffuse with decreasing velocities (rip head) towards offshore for oblique incidence of waves. The rip neck region is located about $80 \mathrm{~m}$ away from the coast for normal incidence. The higher magnitudes of alongshore velocities are observed midway between the shoreline and the breaker line. 


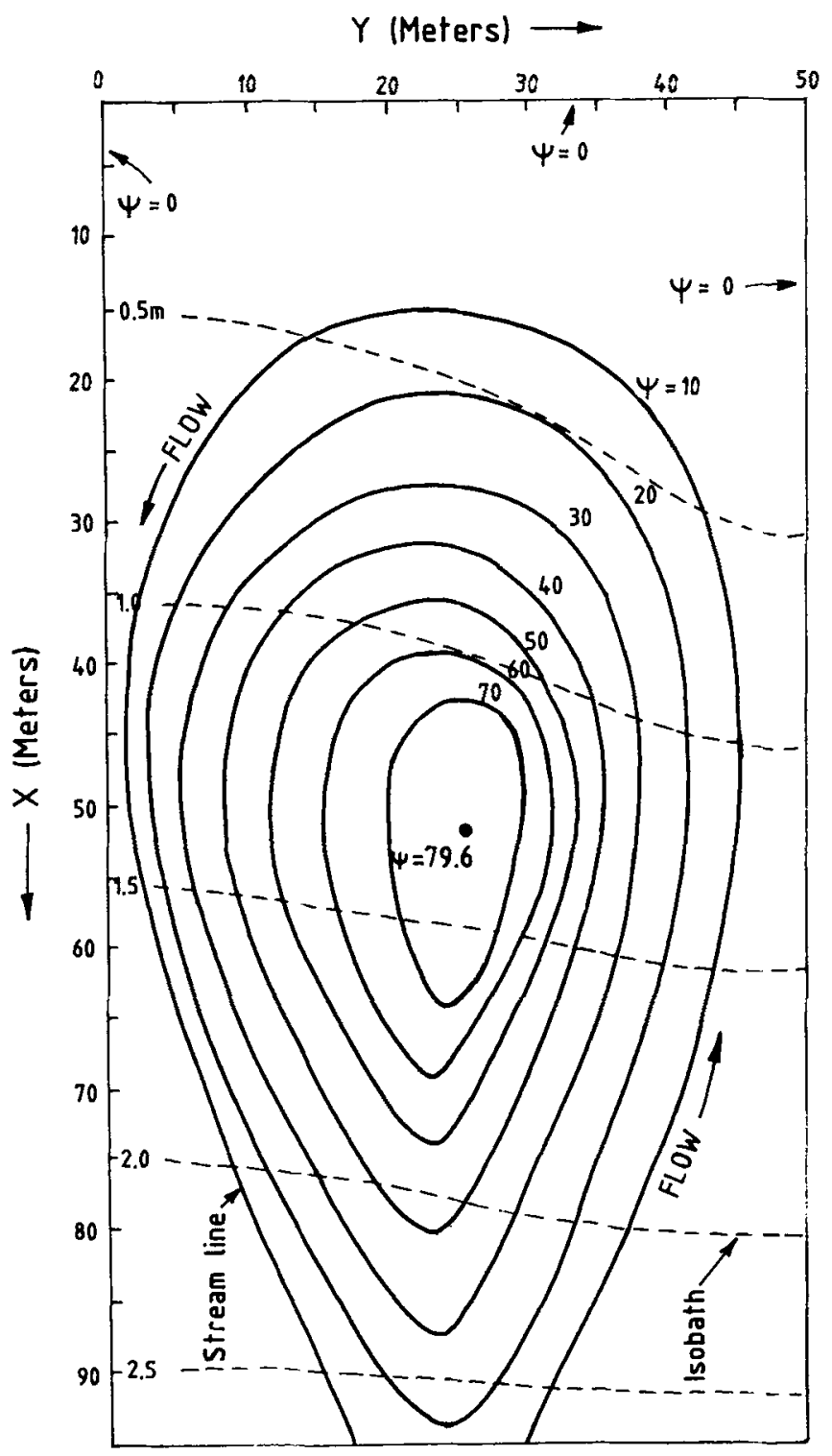

Figure 9. Stream function $\left(\mathrm{m}^{3} \mathrm{~s}^{-1}\right)$ for Calangute (normal wave incidence).

Murty et al (1975) from their field observations of nearshore currents in this area reported the existence of a number of zones of rip currents along this coast. These rips appear to be prevalent prior to the onset and during the monsoon. They reported alongshore current velocities as high as $0 \cdot 1$ to $0.6 \mathrm{~m} / \mathrm{s}$ along this coast. Murty (1977) in a similar study deduced the possible presence of cellular patterns along this coast with scales varying from a few meters to more than $200 \mathrm{~m}$, for waves approaching from WNW, W and SW with a period of $8 \mathrm{~s}$, especially for normal incidence. The flow magnitudes obtained from these field investigations and the ones from the present study are found to be quite comparable except at the points of convergence, where the present study gives slightly higher magnitudes of the order of 0.2 to $0.5 \mathrm{~m} / \mathrm{s}$. As 


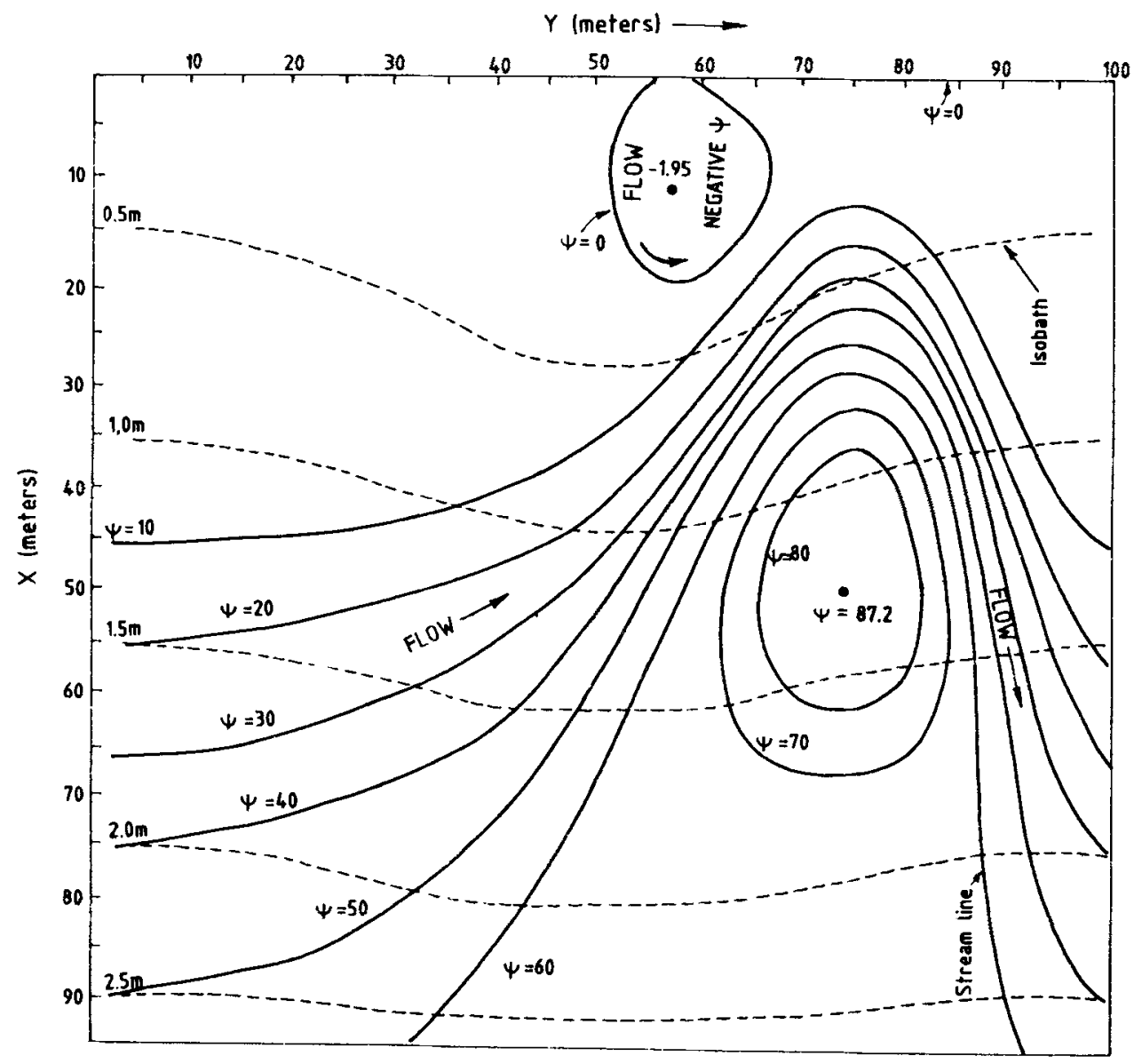

Figure 10. Stream function $\left(\mathrm{m}^{3} \mathrm{~s}^{-1}\right)$ for Calangute (oblique wave incidence).

we are concerned with monochromatic waves in this study, while the real conditions are much more complex due to the superposed local sea, and changes brought about by localized air circulation, there is reason to expect a departure in flow magnitudes. The modifications due to wave-wave and wave-current interactions have not been incorporated here, which could lead to a difference between the observed and computed values.

\section{Acknowledgement}

The authors wish to thank Dr J S Sastry, for his encouragement and keen interest in the study.

\section{List of symbols}

$\bar{c} \quad$ friction coefficient

C phase velocity of wave 


$\begin{array}{ll}d & \text { depth of water column } \\ d_{b} & \text { breaker depth } \\ E c_{g} & \text { flux of energy due to group velocity of waves } \\ E_{X} & \text { flux of energy } \\ F & \text { frictional dissipation term } \\ F_{X} & X \text { component of frictional dissipation } \\ F_{Y} & Y \text { component of frictional dissipation } \\ g & \text { acceleration due to gravity } \\ h & \text { wave height } \\ h_{b} & \text { breaker wave height } \\ k & \text { local wave number } \\ L & \text { wavelength } \\ m & \text { slope of the beach } \\ M M_{X} & X \text { component of radiation stress } \\ M_{Y} & Y \text { component of radiation stress } \\ S_{X X} & X \text {-momentum across } X \text { plane } \\ S_{Y Y} & Y \text {-momentum across } Y \text { plane } \\ S_{X Y} & X \text {-momentum across } Y \text { plane } \\ S_{Y X} & Y \text {-momentum across } X \text { plane } \\ T & \text { wave period } \\ u & \text { onshore/offshore component of flow velocity } \\ v & \text { alongshore component of flow velocity } \\ x & \text { the seaward distance along } X \text { axis } \\ y & \text { the distance of shoreline along } Y \text { axis } \\ Y_{b} & \text { a specific constant indicating one of the boundary lines } \\ \gamma & \text { an empirical constant } \\ \eta & \text { distance between mean sea level and still water level due to the presence } \\ \theta & \text { of waves } \\ \lambda & \text { angle of wave direction } \\ \rho & \text { wavelength of the periodic bottom topography } \\ \psi & \text { density of water } \\ & \text { stream function } \\ & \end{array}$

\section{References}

Anon 1982 Wave (Swell) atlas for Arabian Sea and Bay of Bengal; Nat. Inst. Oceanogr., India

Arthur R S 1962 A note on the dynamics of rip currents; J. Geophys. Res. $672777-2779$

Bowen A J 1969a Rip currents. 1, Theoretical Investigations; J. Geophys. Res 74 5467-5478

Bowen A J 1969b The generation of longshore currents on a plain beach; J. Geophys. Res. 27 206-215

Galvin C J 1972 Wave breaking in shallow water; in Waves on beaches and resulting sediment transport (ed.) R E Meyer (London: Academic Press) pp. 413-456

Krishna Kumar V 1987 Nearshore circulation at some selected places of the coast of Goa; Unpublished MSc Thesis, University of Bombay, p. 92

Longuet-Higgins M S 1970a Longshore currents generated by obliquely incident sea waves; J. Geophys. Res. $756778-6789$

Longuet-Higgins M S 1970 b Longshore currents generated by obliquely incident sea waves; J. Geophys. Res. $756790-6801$

Longuet-Higgins M S 1972 Recent progress in the study of longshore currents; in Waves on heaches and resulting sediment transport (ed.) R E Meyer (London. Academic Press) pp. 203-248 
Longuet-Higgins M S and Stewart R W 1964 Radiation stress in water waves; a physical discussion, with applications; Deep Sea Res. 2 529-562

Murty C S 1977 Studies on the physical aspects of the shoreline dynamics at some selected places along the west coast of India; Unpublished PhD Thesis, University of Kerala, p. 149

Murty C S, Veerayya M and Varadachari V V R 1975 Littoral \& Rip Currents off Calangute Beach, Goa; Indian J. Mar. Sci. 4 1-4

Noda E K 1974 Wave induced nearshore circulation; J. Geophys. Res. 79 4097-4106

Sonu C J 1972 Field observations of nearshore circulations and meandering currents; J. Geophys. Res. 77 $3232-3247$

Thornton E B 1971 Variation of longshore current across the surf zone; Coastal Engg. Vol. 1. Proc. 12th Coastal. Engg. Conj. (New York: Am. Soc. Civil Engineers) pp. 291-308

Veerayya M 1978 Studies on the geological aspects of the beaches of Goa in relation to some meteorological and physical oceanographic factors; Unpublished PhD Thesis, Andhra University, p. 240 